\title{
MORPHOLOGICAL VARIATIONS OF UMBILICAL CORD IN HUMAN
} PLACENTA

\author{
Siva Sree Ranga. M.K *1, Vasantha Mallika. M.C ${ }^{2}$.
}

${ }^{{ }_{1} 1}$ Associate Professor, Department of Anatomy, Sree Mookambika Institute of Medical Sciences, Kulasekharam, South India.

${ }^{2}$ Professor, Department of Community Medicine, Sree Mookambika Institute of Medical Sciences, Kulasekharam, South India.

\section{ABSTRACT}

Introduction: The umbilical cord or Funis forms the connecting link between the fetus and the placenta. Through umbilical cord the fetal blood flows to and from the placenta providing nutrition, gas exchange, waste removal, endocrine function and immune support to the developing fetus. The umbilical cord extends from the fetal umbilicus to the fetal surface of the placenta. Being organs of vital importance for continuation of pregnancy, the placenta and umbilical cord have evolved great interest among the Anatomists, Embryologists, Pathologists and Obstetricians.

Materials and Methods: A cross sectional study was conducted on 695 umbilical cords attached to placentae from the Department of Obstetrics and Gynaecology, collected soon after delivery. The morphology of the umbilical cords attached to placenta were studied. Fresh specimens of umbilical cord were examined for attachment to the placenta, cord length, diameter, number of vessels, diameter of vessels, coiling and knotted appearance. Neonatal details within 24 hours after delivery were recorded.

Results: Average cord length was $46.04 \mathrm{~cm}$ (SD $11.8 \mathrm{~cm}$ ) with the shortest cord being $5.8 \mathrm{~cm}$ and the longest $78.50 \mathrm{~cm}$. Majority of the umbilical cords $(71.94 \%)$ had eccentric attachment to the placentae; (139) $20 \%$ had central and $53(7.63 \%)$ had marginal and $3(0.43 \%)$ had velamentous attachments. Occurrence of furcate insertion of umbilical cord vessels into the placenta was $28 \%$ and non-furcate insertion was 501 (72\%). Morphological variations of umbilical cord showed statistically significant association with maternal Diabetes mellitus, Preeclampsia, Antepartum haemorrhage, twin pregnancy and foetal Intra Uterine Growth Retardation.

Conclusion: The study observed that, the morphological variations of umbilical cord show significant effects on maternal and foetal conditions. These quantitative findings may provide baseline information for further investigations.

KEY WORDS: Umbilical cord, Placenta, Morphology, Variations.

Address for Correspondence: Dr. M K Siva Sree Ranga, Siva Sree Sadanam, Vellarada, Thiruvananthapuram - 695 505, Kerala, India. Phone: +91-9447696069.

E-Mail: dr.sivasreeranga@gmail.com

Access this Article online

Quick Response code

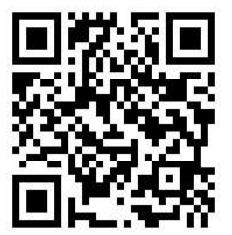

DOI: $10.16965 /$ ijar.2019.226

Journal Information

International Journal of Anatomy and Research

ICV for 2016
90.30
ISSN (E) 2321-4287 | ISSN (P) 2321-8967 https://www.ijmhr.org/ijar.htm DOI-Prefix: https://dx.doi.org/10.16965/ijar

\section{Article Information}

Received: 11 May 2019

Peer Review: 11 May 2019

Revised: None
Accepted: 10 Jun 2019

Published (0): 05 Jul 2019

Published (P): 05 Jul 2019

\section{INTRODUCTION}

The umbilical cord or Funis extends from the fetal umbilicus to the fetal surface of the placenta. It forms the connecting link between the fetus and the placenta [1]. Through umbilical cord the fetal blood flows to and from the Int J Anat Res 2019, 7(3.1):6786-89. ISSN 2321-4287 placenta providing nutrition, gas exchange, waste removal, endocrine function and immune support to the developing fetus [2]. Being organs of vital importance for continuation of pregnancy, the placenta and umbilical cord have evolved great scientific importance among the 
Anatomists, Embryologists, Pathologists and Obstetricians. Morphological Variations of umbilical cord is common and may be associated with abnormal maternal as well as fetal conditions [2]. These morphological variations include umbilical cord attachments to the placenta, extreme umbilical cord lengths, Wharton's jelly content, cord tensile strength, shape, cord looping, cord knotting and variations in umbilical cord vessel morphology and number. Recent studies [3-5] on umbilical cord have been directed into other aspects also recording useful information on the subject. Knowledge about the umbilical cord is important because the vessels in the cord are essential part of foetal circulation. The umbilical cord has also been found to be a marker for intrapartum complications. The present study was planned to find the morphological variations of umbilical cord and factors associated with it in a tertiary care centre, in South India.

\section{OBJECTIVES}

1. To study the morphology of umbilical cords attached to placenta soon after delivery

2. To find morphological variations and factors associated with it among the specimens studied.

\section{MATERIALS AND METHODS}

A Cross sectional study was conducted among 695 specimens of umbilical cords attached to placentae collected soon after delivery from Department of Obstetrics and Gynaecology, Dr.Somervell Memorial CSI Medical College, Karakonam during the period of six months from July 2016. All the umbilical cords with placentae delivered during the study period were collected and included in the study. The specimens were washed under running tap water, labelled and fixed in $10 \%$ formalin. Details of the mothers were recorded. Examination of the umbilical cords with the placentae was carried out. Morphological study of the umbilical cord was done. Fresh specimens of umbilical cord were examined for mode of attachment to the placenta, cord length, diameter, number of vessels, diameter of vessels, coiling and knotted appearance. Neonatal details within 24 hours after delivery were also recorded.
The following observations were noted and recorded:

\section{A. Morphology of Umbilical cord:}

1) Mode of attachment of umbilical cord to the placenta.

2) The length of umbilical cord.

3) Diameter of the umbilical cord.

4) Number of vessels in the umbilical cord.

5) Insertion of the umbilical vessels into the placentae.

6) Diameter of vessels in the umbilical cord.

7) Coiling of umbilical cord.

8) Knotted appearance of umbilical cord.

9) Looked for cord abnormalities.

Variations in the morphology of umbilical cord: Looked for any abnormal cord length, shape, abnormal mode of attachment of umbilical cord with placenta, presence of knots, single umbilical artery or any other variations.

\section{B. Maternal Details:}

Gestational age, Parity, Weight at delivery, any conditions such as Hypertension, Diabetes, Preterm labor.

C. Neonatal Details: Birth weight, Congenital Malformations

\section{OPERATIONAL DEFINITIONS:}

Normal length of umbilical cord: $40 \mathrm{~cm}$ ( usual variation of $30-100 \mathrm{~cm}$ ). The cord is described as short, when the length is less than $20 \mathrm{~cm}$, Long cord when the length is $>40 \mathrm{~cm}$. Very long cord may measure $101-300 \mathrm{~cm}$. Long cord may loop round the neck (20-30\%).

Normal Diameter of Umbilical cord: $1.5 \mathrm{~cm}$ (with variation of $1-1.25 \mathrm{~cm}$ )

Thickness is not uniform, but presents with nodes or swellings at places due to kinking of umbilical vessels or due to local collection of Wharton's jelly. True knots are usually rare (1\%).

Attachment of cord: Usually umbilical cord is attached between the centre and edge of the placenta ( eccentric). Attachment may be central, marginal or even on the chorion leave at varying distance away from the margin of the placenta called velamentous insertion. 
The insertion of the umbilical vessels into the placentae: is described as either furcate (when the vessels are separated from each other before their insertion) or non-furcate (when they were covered by a sheath of Wharton's jelly to their point of insertion).

Data collection tool: Pretested proforma

Data were collected after obtaining Ethical Committee Clearance from the Institutional Ethics Committee and Informed consent from the pregnant mothers.

Data entry and analysis: Data were entered in MS Excel sheet and analysis was done using Statistical software SPSS Trial version 20.0

\section{RESULTS AND DISCUSSION}

The present study was conducted among 695 fresh specimens of umbilical cords attached to placenta collected soon after delivery during a period of six months from July 2016.

A. Maternal factors: The mean age of pregnant mothers was $26.13+4.71$ with minimum age 19 and maximum age 41 years.

$7.19 \%$ of the umbilical cords were obtained following preterm labor with prominent maternal risk factors such as Pregnancy Induced Hypertension (60\%) and Gestational Diabetes Mellitus (20\%). Other risk factors were Low prepregnancy weight of mother $4(8 \%)$, Anemia 2 (4\%), Multiple (twin) gestation 1 (2\%), Antepartum hemorrhage $1(2 \%)$, Cervical incompetence 1 (2\%) and Hypothyroidism 1 (2\%).

Table 1: Distribution based on term of labor.

\begin{tabular}{|c|c|}
\hline $\begin{array}{c}\text { Term of pregnancy } \\
\text { at delivery }\end{array}$ & $\begin{array}{c}\text { Number } \\
\text { (Percentage) }\end{array}$ \\
\hline Term labor & $645(92.81)$ \\
\hline Preterm labor & $50(7.19)$ \\
\hline Total & $695(100)$ \\
\hline
\end{tabular}

B. Neonatal Details: ' $Z$ ' test showed significant association of morphological variations of umbilical cord and adverse fetal outcome ( $p$ value less than 0.05).

Morphological variation of umbilical cord in the form of presence of single umbilical artery showed statistically significant association with maternal Diabetes mellitus, Preeclampsia, Antepartum haemorrhage, twin pregnancy and foetal Intra Uterine Growth Retardation.
Table 2: Comparison of Pregnancy outcome and morphological variations of Umbilical cord.

\begin{tabular}{|c|c|c|c|c|}
\hline \multirow[b]{2}{*}{ Foetal outcome } & \multirow[b]{2}{*}{ Component } & \multicolumn{2}{|c|}{ Number (percentage) } & \multirow[b]{2}{*}{ Significance } \\
\hline & & $\begin{array}{c}\text { Variations } \\
\text { present }\end{array}$ & Normal cord & \\
\hline \multirow{2}{*}{ Mode of delivery } & Vaginal & Nil & $645(92.81)$ & \multirow{8}{*}{$P$ value $>0.05$} \\
\hline & LSCS & $50(7.19)$ & $\mathrm{Nil}$ & \\
\hline \multirow{2}{*}{ Baby at birth } & Live & $48(6.9)$ & $645(92.81)$ & \\
\hline & Dead & $2(0.28)$ & Nil & \\
\hline \multirow{2}{*}{ NICU admissions } & Yes & $39(5.6)$ & $1(0.14)$ & \\
\hline & No & $41(5.9)$ & $643(92.5)$ & \\
\hline \multirow{2}{*}{$\begin{array}{l}\text { Congenital } \\
\text { anomalies }\end{array}$} & Yes & $9(1.3)$ & Nil & \\
\hline & No & $2(0.28)$ & $\mathrm{Nil}$ & \\
\hline
\end{tabular}

\section{Findings in the Umbilical cord:}

Length of umbilical cord: Mean length of the cord was $46.04 \mathrm{~cm}$ (SD $11.8 \mathrm{~cm}$ ) with the shortest cord being $5.8 \mathrm{~cm}$ and the longest $78.50 \mathrm{~cm}$.

Using the mean cord length $(\geq 40 \mathrm{~cm})$ as a marker, the distribution of short and long cords were $20.56 \%$ and $79.44 \%$ respectively. This difference in mean cord length was statistically significant.

Long cords were associated with cord prolapse and cord entanglement round the neck or body leading to compression of cord vessels and fetal distress.

Peter Kwabena Appiah (2009) [6], studied 265 umbilical cords and reported the average length of the cord as $44.8 \mathrm{cms} \pm 12.0$. The study done by Gupta. S, et al [7] reported the average length of the cord as $44.3 \mathrm{cms} \pm 9.2$.

The diameter of the cords was in the range of $1.50 \mathrm{~cm}$ to $3.20 \mathrm{~cm}$. Mean cord diameter was $2.1 \mathrm{~cm}(S D$ 0.004), with a 95\% confidence interval.

Mode of attachment of cord to the placenta: In the present study, majority of the umbilical cords 500 (71.94\%) had eccentric attachments to the placentae; (139) $20 \%$ had central and $53(7.63 \%)$ had marginal and $3(0.43 \%)$ had velamentous attachments.

Umbilical cords of placentae with Pregnancy Induced Hypertension, showed abnormal insertion of cord. Among them, most of them showed marginal insertion and three specimens showed velamentous insertion of umbilical cord. There was insignificant association between insertion of umbilical cord and PIH ( $\mathrm{P}>0.05)$.

Peter Kwabena Appiah [8] found the site of insertion of umbilical cord on placenta was eccentric in $21.14 \%$, central in $60.75 \%$ and marginal in $18.11 \%$. 
Many authors Udaina et al [9]., Majumdar and Dasgupta [10], Yousuf M S et al [11] and Vijayalakshmi B Kittali [12] observed that marginal insertion of cord was significantly associated with hypertensive placentae.

Number of vessels in the umbilical cord: In the present study it was found that umbilical cord had 2 arteries and 1 vein in 648 specimens which includes 639 normal pregnancies, 6 hypertensive pregnancies and in 2 multiple pregnancies. Persistence of the right umbilical vein results in a 4 vessel umbilical cord ( 2 veins and 2 arteries) is seen in conjoint twins [13].

The single umbilical artery and single umbilical vein were observed only in 6 umbilical cords. Presence of single umbilical artery showed statistically significant association with maternal Diabetes mellitus, Preeclampsia, Antepartum haemorrhage, twin pregnancy and foetal Intra Uterine Growth Retardation.

Insertion of the umbilical vessels into the placentae: Occurrence of furcate insertion of umbilical cord vessels into the placenta was $28 \%$ and non-furcate insertion was 501(72\%).

Coiling of umbilical cord: This coiling arises as the longer umbilical vein twists around the umbilical arteries providing strength to the umbilical vessels. Non-coiled cords and poorly coiled cords are less able to resist compressive forces. This may lead to preterm delivery, fetal distress and intrauterine death. Over coiled cords may lead to foetal demise, intrauterine growth retardation, thrombosis of chorionic vessels and umbilical veins and stenosis of the umbilical cord [14].

Knotted appearance of umbilical cord: The umbilical cord can become knotted. If the knot is loose, fetal circulation is 'maintained. If the knot is tightened during the foetal descent through the birth canal, can occlude the placental circulation and lead to intrauterine death of the foetus [15]. In the present study, the umbilical cord of one of the demised babies showed knots.

\section{CONCLUSION}

The morphological variations of umbilical cord showed significant effects on maternal and foetal conditions. These quantitative findings may provide baseline information to the researchers for further investigations

Conflicts of Interests: None

\section{REFERENCES}

[1]. Asra A, Suseel amma D, Sarita S, Ramani T V, Nagajyothi D. Study of morphological variations of 50 placentae with umbilical cords and its developmental relevance. Int J Anat Res. 2015;3(3):125966.

[2]. Tangirala S, kumari D. Placental morphology in hypertensive disorders and its correlation to neonatal outcome. IAIM 2015;2:35-8.

[3]. Sornes,T.Umbilical cord knots. Acta Obstet Gynaecol Scand Mar;79(3): 157-159

[4]. Calvano,C.J., Hoar,R.M., Mankes,R.F., Lefevre,R., Reddy,P.P., Moran,M.E.\& Mandell, J. Experimental study of umbilical cord length as a marker offetal alcohol syndrome.Teratology, 2000;61(3):184-188.

[5]. Pennati G. Biochemical properties of the human umbilical cord, Biorheology. 2001;38(5-6):355-366.

[6]. Peter Kwabena Appiah. Relationship between the morphology of placenta, Umbilical cord and Perinatal Outcome,2009.

[7]. Gupta, S., Faradi, M. M. A and Krishnan, J. Umbilical cord Index. Journal of Gynecology, India, 2006;56(4):315-319.

[8]. Peter Kwabena Appiah. Relationship between the morphology of placenta, Umbilical cord and Perinatal Outcome,2009.

[9]. Udaina A, Bhagwat SS, Mehta CD. Relation between placental surface area, infarction and foetal distress in pregnancy induced hypertension with its clinical relevance. J Anat Soc India 2004;53:27-30.

[10]. Majumdar S, Dasgupta H. A study of placenta in normal and hypertensive pregnancies. J Anat Soc India 2005;54:1-9.

[11]. Yousuf M S, Tarannum Y, Naval K P. Variations in the placental attachment of umbilical cord and its clinical significance. Journal of Medical and Dental Science. 2016;1-7.

[12]. Vijayalakshmi B, Kittali S. Morphological changes of placenta in cases of pre-eclampsia and perinatal outcome. Int J Sci Stud 2015;3:137-42.

[13]. Rodriguez MA four-vessel umbilical cord without congenital abnormalities. South Med J 1984 Apr;77(4):539.

[14]. Machin, G. A., Ackerman, J. and Gilbert-Barness, E. Abnormal umbilical cord coiling is associated with adverse perinatal outcomes. Paediatric and Developmental Pathology, 2000;3:465-471.

[15]. Cunningham FG, Gant NF, Leveno KJ, Gilstron LC, Hauth JC, Wenstrom KD. Abnormalities of the umbilical cord. Williams Obstetrics. 21st ed. New York: McGraw-Hill Medical Publishing Division, 2001;831-835.

How to cite this article: Siva Sree Ranga. M.K, Vasantha Mallika. M.C. MORPHOLOGICAL VARIATIONS OF UMBILICAL CORD IN HUMAN PLACENTA. Int J Anat Res 2019;7(3.1):6786-6789. DOI: 10.16965/ijar.2019.226 